\title{
The frequency of obstructive sleep apnea in patients with primary Sjogren's syndrome
}

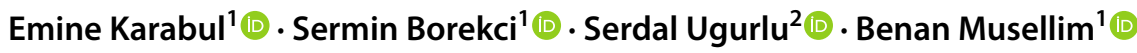

Received: 26 April 2021 / Revised: 28 August 2021 / Accepted: 9 September 2021 / Published online: 12 November 2021

(c) The Author(s), under exclusive licence to Springer Nature Switzerland AG 2021

\begin{abstract}
Introduction There is a lack of information about the frequency of obstructive sleep apnea (OSA) in primary Sjogren's syndrome (pSS). Using all-night polysomnography (PSG), this study aimed to investigate the frequency of OSA in pSS and the factors affecting the frequency of OSA in this condition.

Methods Consecutive patients with pSS who presented to the Collagen Tissue Diseases follow-up polyclinic of the Department of Chest Diseases between 1 April 2019 and 31 December, 2020, were included in the study. Demographic characteristics, chronic diseases, smoking history in pack-years, anthropometric data, Epworth Sleepiness Scale score, pulmonary function test parameters, current thorax computed tomography findings, and PSG data were recorded. The control group was created by the retrospective screening of patients admitted to the sleep polyclinic and who underwent PSG but did not have pSS.

Results OSA was detected in 37 (84\%) of 44 patients with pSS who underwent PSG. Of 37 patients with OSA, $25(68 \%)$ had moderate or severe OSA. Snoring and witnessed apneas, REM\%, snoring index, and maximum apnea and maximum hypopnea duration were statistically significantly lower in the pSS group compared with the control group $(p<0.001, p=0.003$, $p=0.025, p=0.001, p=0.028$, and $p=0.035$, respectively).

Conclusion The frequency of OSA in patients with pSS was $84 \%$, with a decrease in REM\%. Although a correlation between symptoms suggesting OSA and the presence of radiological lung involvement, spirometry, and DLCO values with OSA could not be demonstrated, physicians are recommended to be attentive for the presence of OSA in all patients with pSS and to investigate OSA using PSG.
\end{abstract}

Keywords OSA · Primary Sjogren's syndrome · PSG · Frequency · Sjogren's syndrome

\section{Introduction}

Sjögren's syndrome (SS) is a chronic autoimmune disease of unknown cause, characterized by glandular and extraglandular involvement, most commonly affecting the salivary and lacrimal glands, and lymphocytic infiltration of exocrine glands [1]. It is referred to as primary SS (pSS) if it occurs alone without any other connective tissue disease. The prevalence of pSS is approximately $0.1-0.5 \%$ in the

Sermin Borekci

borekcisermin@gmail.com

1 Department of Pulmonary Diseases, Cerrahpasa Medical Faculty, Istanbul University-Cerrahpasa, Istanbul 34098, Turkey

2 Department of Rheumatology, Cerrahpasa Medical Faculty, Istanbul University-Cerrahpasa, Istanbul, Turkey population. It can occur at any age, with the first highest incidence at 20-30 years and the second peak in the 50s. pSS is seen 9-10 times more commonly in women than in men [2]. The most common symptoms are dry mouth and eyes. Dryness in the upper respiratory tract and all airway mucosa, inflammation, deterioration of mucociliary clearance, and increased mucus viscosity cause the related symptoms. Subjective findings such as excessive daytime sleepiness (EDS), body pain, and depression, especially fatigue, are common in patients with $\mathrm{pSS}$, and their etiopathogenesis have not been elucidated $[1,3]$.

Obstructive sleep apnea (OSA) occurs due to complete or partial obstruction of the upper airways during sleep. It is characterized by snoring, apnea, nocturnal desaturation, and EDS [4]. Symptoms, cognitive disorders, and fatigue can be seen due to nighttime respiratory events and complications. The main problem in OSA is upper respiratory 
tract narrowing. There are many mechanical and inflammatory causes in the pathophysiology of this narrowing. Its prevalence in the adult population is $4 \%$ in men and $2 \%$ in women [5].

Primary SS can cause airway involvement, especially upper airway involvement, with lymphocytic infiltration. It causes dryness in the entire respiratory tract mucosa by affecting the airway gland structures. Thus, it has been hypothesized that pSS facilitates upper airway collapse and may increase the risk of OSA by contributing to its pathophysiology. Symptoms such as EDS and fatigue in patients with pSS may be due to the underlying OSA. The prevalence of fatigue symptoms, which is also common in OSA, was found to be $38-88 \%$ in pSS patients, while it was $0.007-2.8 \%$ in the general population [6]. On the other hand, it has not been demonstrated whether or not radiologic lung involvement and the decrease in respiratory functions contribute to the risk of OSA in patients with pSS.

Sleep-related problems and sleep disorders in pSS have been investigated frequently, but there are few studies on the use of polysomnography (PSG) in investigating sleepdisordered breathing $[7,8]$. There is scant information about the frequency of OSA in pSS. This study aimed to investigate the frequency of OSA in pSS and its affecting factors using all-night PSG, which is the gold standard test in the diagnosis of OSA.

\section{Materials and method}

The study was planned as a prospective, controlled, crosssectional study. Ethics committee approval for the study was obtained from the Ethics Committee of Istanbul University-Cerrahpasa, Cerrahpasa Medical Faculty (IRB No. 604.01.01-45638).

\section{Participants}

The study group was formed from consecutive patients with pSS who presented to the Collagen Tissue Diseases followup polyclinic of the Department of Chest Diseases between 1 April 2019 and 31 December 2020 pSS was diagnosed by the rheumatology department according to the guidelines [9]. The patients were evaluated according to the inclusion criteria (diagnosis of pSS, age 18 years or older, and agreement to participate in the study obtained with written consent) and exclusion criteria (the association of another connective tissue disease or chronic diseases such as idiopathic pneumonia with interstitial involvement, sarcoidosis, amyloidosis, acromegaly, heart failure, active cancer, pregnancy, insufficient sleep time in PSG, or technically unsuitable PSG data).
Demographic characteristics, chronic diseases, smoking history in pack-year terms, anthropometric data, dry mouth, dry eye, snoring, witnessed apnea, and EDS of all patients was questioned and recorded. Salivary gland biopsy, dry eye assessment test (Schirmer test), serologic tests (anti-Ro/SSA, anti-La/SSB, RF, ANA) were recorded before diagnosing pSS. Epworth Sleepiness Scale (ESS) scores, pulmonary function test (PFT) parameters [spirometry and diffusing capacity of the lung for carbon monoxide (DLCO)], current thorax computed tomography (CT) findings, and PSG data were recorded.

The control group was created with the retrospective assessment of patients admitted to the sleep polyclinic during the study period who had PSG but were not diagnosed as having pSS. Female, non-pregnant patients aged over 18 years with normal chest radiography and acceptable PSG results without any connective tissue diseases such as sarcoidosis, amyloidosis, acromegaly, and active cancer diagnoses were included.

\section{Anthropometric data}

The height $(\mathrm{cm})$, weight $(\mathrm{kg})$, and body mass index (BMI) $\left(\mathrm{kg} / \mathrm{m}^{2}\right)$ of the patients were recorded. Neck circumference $(\mathrm{cm})$ was measured at the level of the cricothyroid membrane and recorded. BMI was classified as normal $(18.5-24.9 \mathrm{~kg} /$ $\mathrm{m}^{2}$ ), overweight $\left(25-29.9 \mathrm{~kg} / \mathrm{m}^{2}\right)$, and obese $\left(>30 \mathrm{~kg} / \mathrm{m}^{2}\right)$ [10].

\section{Polysomnography}

All-night polysomnography (PSG) recording of all patients included in the study was performed with SOMNOscreen plus system (SOMNOscreen, SOMNOmedics, Germany). PSG records were evaluated by two different experts at different times, according to the AASM's "Manual for Scoring Sleep-Version 2" scoring criteria update in 2012, and a report was written for each patient with a consensus. During recording, electroencephalography (EEG), electrooculography (EOG), electromyography (EMG), electrocardiography (ECG) electrodes, nasal cannula, thermistor, abdominal and chest belts, tracheal microphone, pulse oximeter, and position sensor were used based on the AASM 2007 recording protocol. Sleep duration, efficiency, duration, and percentages of sleep phases, sleeping time, and percentages in the supine and non-supine positions were noted. All respiratory events, apnea and hypopnea indexes (AHI) per sleep hour, fingertip oxygen saturation follow-up values, and oxygen desaturation indexes (ODI) were recorded. For scoring hypopnea, the criterion of a $50 \%$ or more decrease in airflow lasting at least $10 \mathrm{~s}$ and accompanying a $3 \%$ decrease in oxygen saturation or arousal was used. Apnea was defined as an interruption of the airflow for $10 \mathrm{~s}$ [11]. For sufficient 
PSG registration, at least $4 \mathrm{~h}$ of sleep time and at least $60 \%$ sleep efficiency were accepted.

AHI was used to define OSA. Patients with $\mathrm{AHI} \geq 5$ were considered as having OSA, and those with an AHI of 5-14, $15-29$, and $\geq 30$ were classified as having mild, moderate, and severe OSA. Rapid eye movement (REM)-dependent OSA was described as AHI being $\geq 5$ with AHI $<5$ during the non-REM period and AHI during the REM period being twice as much it was during the non-REM period [12, 13]. Similarly, "Position-dependent OSA" was described as $\mathrm{AHI} \geq 5$ with $\mathrm{AHI}<5$ in the supine position and $\mathrm{AHI}$ in a supine position being more than twice as much as it was in the non-supine position $[12,13]$.

The ESS was used to determine the patients' EDS subjectively, and its score was recorded. The ESS is an easy-to-use questionnaire consisting of 8 questions [14]. Each question is scored between 0 and 3 points. The total scores varied between 0 and 24, and EDS was considered to be present with ESS over 10 points.

PFT Spirometry and DLCO tests results [forced vital capacity (FVC), FVC\%, forced expiratory volume in $1 \mathrm{~s}$ (FEV1), FEV1\%, FEV1/FVC, FEV1/FVC\%, DLCO, alveolar volume (VA), DLCO/VA, DLCO/VA\% values] were recorded. The tests were conducted using a ZAN 100 Flow Handy II device according to the European Respiratory Society and American Respiratory Society (ERS/ARS) criteria [15, 16].

Thorax CT Chest radiographs of the control group and thorax CT reports of the pSS group were recorded. Pleural effusion, interstitial involvement patterns on thoracic CTs [non-specific interstitial pneumonia (NSIP), lymphocytic interstitial pneumonia (LIP), usual interstitial pneumonia (UIP), organized pneumonia (OP)], presence of bronchiectasis, and the number of segments involvement was assessed by two expert radiologists. Evaluations were made at different times, and the final report was written by ensuring a common consensus for each patient. Ten segments were evaluated in the right lung, and eight segments were evaluated in the left lung according to the final report.

\section{Statistics and analysis}

All analyses were performed using the SPSS v21 (SPSS Inc., Chicago, IL, USA) program. The compliance of quantitative variables to normal distribution was checked using the Kolmogorov-Smirnov test. Quantitative variables are summarized using mean \pm standard deviation and median (lowest value-most considerable value), and qualitative variables are summarized as frequency (percentage). According to the pSS and control groups, analysis of quantitative variables was performed using the independent samples $t$ test or the Mann-Whitney $U$ test according to their suitability to normal distribution. According to OSA weight status, analysis of quantitative variables was performed using the Kruskal-Wallis test based on the conformity to normal distribution. Bonferroni correction was used for binary comparisons. Qualitative variables were analyzed using the chi-square test or Fisher's exact test. Values of $p<0.05$ were considered statistically significant.

\section{Results}

Eighty-one patients with pSS were evaluated within the specified time interval. A total of 47 patients who met the inclusion criteria were included in the study; three patients were excluded due to insufficient sleep time. From among 740 patients who underwent PSG (486 M/254 F), 88 female patients without pSS were selected for the control group (see Fig. 1: Flow chart). The demographic characteristics of the pSS group are given in Table 1. Table 1 also shows the symptoms, laboratory findings, Schirmer test result, salivary gland biopsy result, spirometry test, and DLCO values of the pSS group. Anti-Ro/SSA positivity (57\%) was the most common among the rheumatological markers examined. Dry mouth (66\%) and dry eyes (75\%) were also common symptoms.

An interstitial involvement pattern was detected in 15 (34\%) of the 44 patients with pSS (Table 1). No pleural effusion was detected in any patient.

OSA was detected in $37(84 \%)$ of 44 patients [no OSA:7 (16\%); mild OSA:12 (27\%); moderate OSA:19 (43\%); severe OSA:6 (14\%)] with pSS who underwent PSG. A statistically significant relationship was found between the presence of OSA and age, BMI, and being overweight or obese ( $p=0.016, p=0.016$, and $p=0.012$, respectively). Complaints suggestive of OSA, presence, and extent of radiological lung involvement, spirometry and DLCO values were not associated with OSA in the pSS group (Table 2).

There was no statistical difference between the control group and the pSS group in terms of age, gender, BMI, weight, height, obesity, neck circumference, comorbidities, smoking history in pack-years, and smoking status (Table 3).

There was no statistical difference between pSS and control groups in terms of OSA frequency [37 of 44 patients (84\%) in the pSS group; 68 of 88 patients (77\%) in the control group, $p=0.359$ ], also there was no statistical difference in terms of OSA severity and AHI values (mean AHI value, $15.1 \pm 11.4$ in the pSS group; $17.4 \pm 15.6$ in the control group, $p=0.820$ ) (Table 3). Snoring, witnessed apnea, REM\%, snoring index, and maximum apnea and maximum hypopnea duration were statistically significantly lower in 


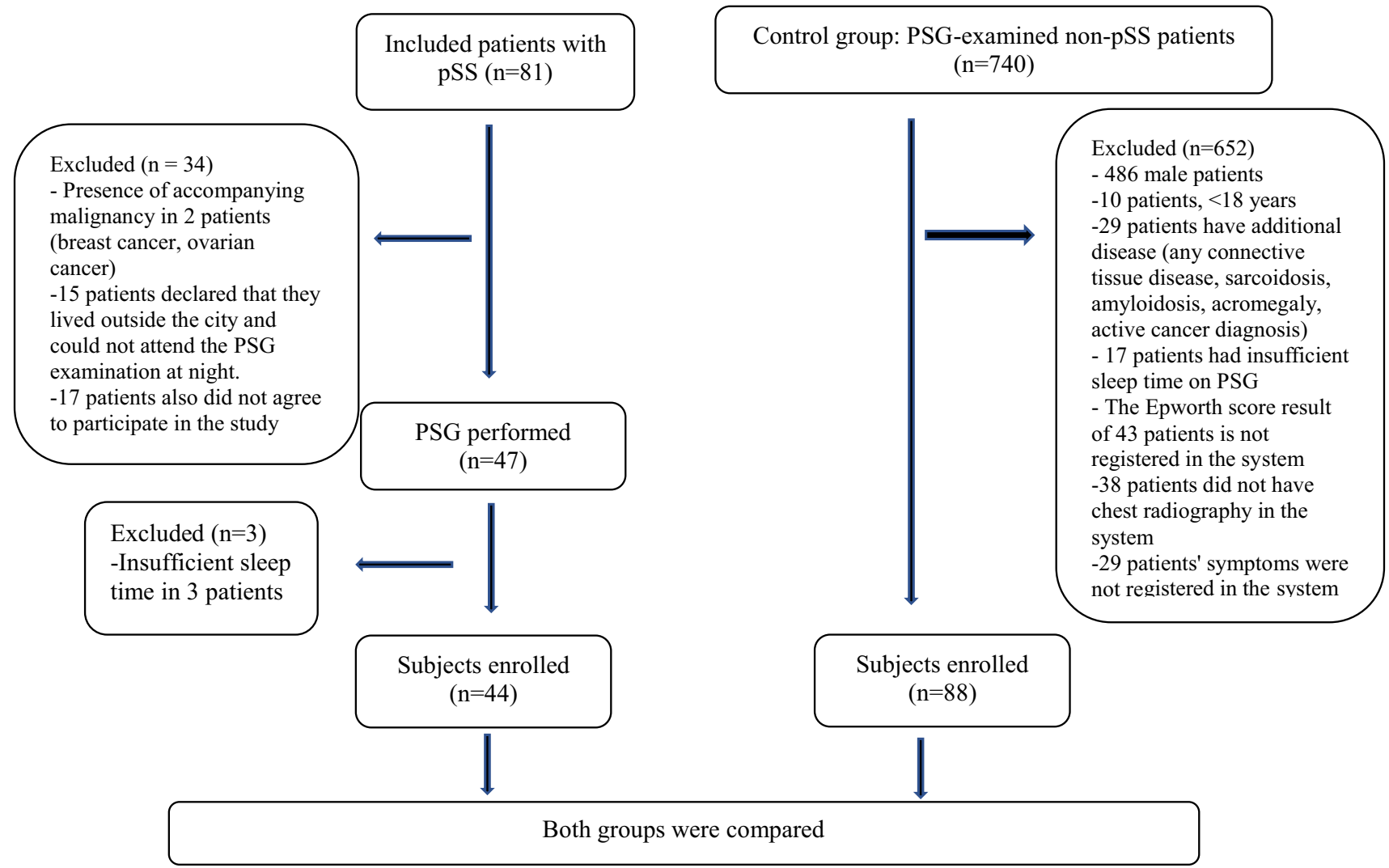

Fig. 1 Flow chart

the pSS group compared with the control group $(p<0.001$, $p=0.003, p=0.025, p=0.001, p=0.028$, and $p=0.035$, respectively) (Table 3 ).

\section{Discussion}

Our study found that the frequency of OSA was $84 \%$ in patients with $\mathrm{pSS}$, and REM\%, snoring index, maximum apnea, and hypopnea time decreased in patients with pSS with OSA. Symptoms suggesting OSA, radiologic pulmonary involvement, spirometry, and DLCO values were not found to be associated with OSA.

In pSS, there are two studies investigating OSA with PSG. In the study of Usmani et al., which consisted of 28 patients with pSS and 18 healthy controls, $64 \%$ of the patients had OSA. In the study of Jülich et al., not including a control group of 14 patients with pSS, $28.5 \%$ were diagnosed as having OSA $[7,8]$. In our study, this rate was $84.1 \%$. The high ratio of moderate and severe OSA were remarkable. This high rate shows that the presence of OSA is substantial in patients with pSS and requires attention.

It has been reported that OSA is most common at the ages of 40-60 years in the general population [17]. No relationship was found between age and OSA in Jülich et al.'s study [8]. In our study, a significant relationship was found between age and the presence of OSA. Studies with more extensive series are needed on this subject.

It has been reported that the risk and severity of OSA increase with increased BMI [18]. In patients with pSS, Jülich et al. reported that BMI was not associated with OSA [8]. However, in our study, a relationship was found between BMI and the presence and severity of OSA in patients with pSS. Our result shows that BMI is associated with OSA risk in patients with pSS, similar to the normal population. It may be necessary to be more careful in terms of OSA in overweight and older pSS patients.

Neck circumference is a risk factor for OSA in the general population [19]. In pSS, neck circumference has not been investigated previously. Regarding rheumatologic diseases, Gundogdu et al. found no relationship between neck circumference and the presence of OSA in patients with systemic sclerosis [20]. In our study, the increase in neck circumference was not associated with OSA risk in pSS.

The risk of OSA is increased in heavy smokers [21]. No study has examined the relationship between smoking and OSA in patients with pSS. In our study, smoking status 
Table 1 Clinical, demographic, laboratory, pulmonary function tests, and radiologic characteristics of patients with pSS

\begin{tabular}{|c|c|}
\hline \multicolumn{2}{|l|}{ Parameters } \\
\hline Female/male, $n$ & $42 / 2$ \\
\hline Age (year), mean $\pm \mathrm{SD}$ & $56.3 \pm 13.3$ \\
\hline Body mass index $\left(\mathrm{kg} / \mathrm{m}^{2}\right)$, mean $\pm \mathrm{SD}$ & $29.0 \pm 4.6$ \\
\hline Neck circumference $(\mathrm{cm})$, mean $\pm S D$ & $35.0 \pm 2.8$ \\
\hline Duration of illness (year), mean $\pm S D$ & $5.8 \pm 4.5$ \\
\hline \multicolumn{2}{|l|}{ Smoking } \\
\hline Never smoker $(\%)$, mean \pm SD & $68 \pm 9$ \\
\hline Former smoker $(\%)$, mean $\pm \mathrm{SD}$ & $21 \pm 4$ \\
\hline Current smoker $(\%)$, mean \pm SD & $11 \pm 4$ \\
\hline Smoking (pack-year), mean \pm SD & $4.6 \pm 9.1$ \\
\hline \multicolumn{2}{|l|}{ pSS laboratory, $n(\%)$} \\
\hline RF positivity & $14(32)$ \\
\hline ANA positivity & $20(46)$ \\
\hline Anti-Ro/SSA positivity & $25(57)$ \\
\hline Anti-La/SSB positivity & $14(32)$ \\
\hline Shirmer test positivity, $n(\%)$ & $25(57)$ \\
\hline Salivary gland biopsy supporting pSS, $n(\%)$ & $26(59)$ \\
\hline \multicolumn{2}{|l|}{ Symptoms suggestive of pSS, $n(\%)$} \\
\hline Dry mouth & $29(66)$ \\
\hline Dry eyes & $33(75)$ \\
\hline \multicolumn{2}{|l|}{ Pulmonary function tests } \\
\hline $\mathrm{FVC}(\mathrm{L})$, mean $\pm \mathrm{SD}$ & $2.70 \pm 0.74$ \\
\hline $\mathrm{FVC}(\%)$, mean $\pm \mathrm{SD}$ & $101.6 \pm 16.9$ \\
\hline FEV1 $(\mathrm{L})$, mean $\pm \mathrm{SD}$ & $2.15 \pm 0.56$ \\
\hline FEV1 $(\%)$, mean \pm SD & $96.0 \pm 17.4$ \\
\hline FEV1/FVC $(\%)$, mean \pm SD & $79.7 \pm 6.9$ \\
\hline DLCO $(\mathrm{mL} / \mathrm{min} / \mathrm{mmHg})$, mean $\pm \mathrm{SD}$ & $16.8 \pm 6.0$ \\
\hline $\operatorname{DLCO}(\%)$, mean \pm SD & $75.3 \pm 23.2$ \\
\hline \multicolumn{2}{|l|}{ Radiologic findings, $n(\%)$} \\
\hline Interstitial involvement & $15(34)$ \\
\hline Number of segments involved, mean \pm SD & $12.9 \pm 3.4$ \\
\hline \multicolumn{2}{|l|}{ Comorbidities, $n(\%)$} \\
\hline Diabetes mellitus & $7(16)$ \\
\hline Hypertension & $15(34)$ \\
\hline Cardiovascular disease & $3(7)$ \\
\hline \multicolumn{2}{|l|}{ Symptoms suggestive of OSA, $n(\%)$} \\
\hline EDS & $33(75)$ \\
\hline Snore & $13(30)$ \\
\hline Witnessed apnea & $27(61)$ \\
\hline
\end{tabular}

ANA anti-nuclear antibody, $D L C O$ carbon monoxide of the lung diffusing capacity, $E D S$ excessive daytime sleepiness, $F E V 1$ forced vital capacity 1 . Second; $F V C$ forced vital capacity, $O S A$ obstructive sleep apnea syndrome, $p S S$ primary Sjögren syndrome, $R F$ rheumatoid factor

and pack-year smoking were not associated with OSA in patients with pSS.

Jülich et al. found a positive correlation between dry mouth and AHI values in patients with $\operatorname{pSS}(p=0.002)$; there was no relationship between dry eye and OSA. It was commented that dry airways might cause OSA by increasing airway tension [8]. Dry mouth can be a guide in predicting the risk of OSA as an indicator of upper respiratory tract dryness, but Jülich et al.'s study included 14 patients. In our study, no relationship was found between the symptoms of dry mouth and eyes and OSA. Studies with more extensive series are needed on this subject.

Salivary gland biopsy in pSS may be an indicator of upper airway inflammation. In our study, no relationship was found between OSA and the presence of salivary gland biopsy supporting SS. No comparison could be made because there no other studies have investigated this issue.

Snoring and witnessed apnea were not examined in studies evaluating OSA in pSS [7, 8]. In our study, when patients with and without OSA were compared, no difference was found regarding the frequency of snoring and witnessed apnea. Also, the frequency of witnessed apnea and snoring and the snoring index value in PSG were significantly lower in patients with pSS compared with the control group. These findings suggest that witnessed apnea and snoring may be insufficient in predicting the presence of OSA in pSS. For this reason, we recommend that patients with pSS without snoring and witnessed apnea should also be evaluated using PSG for the presence of OSA.

EDS is the most common symptom in patients with OSA in the general population, also a common symptom in pSS. In a systematic review, Hackett et al. determined that there was more EDS in patients with pSS than in healthy controls. It was thought that EDS seen in pSS might be related to sleep disorders [22]. Gudbjörnsson et al. showed that the pSS group had five times more EDS than RA and three times more than the healthy control group [23]. Usmani et al. found that EDS was significantly higher in patients with pSS than in controls $(p=0.014)$ [7]. By contrast, we found no relationship between OSA and EDS in patients with pSS.

In the study of Usmani et al. no relationship was found between ESS score and AHI in patients with pSS, and in the study of Jülich et al., no relationship was found between the ESS score and the presence of OSA [7, 8]. Similarly, in our study, we found no relationship between ESS scores and the presence and severity of OSA in the pSS group.

No study has investigated the relationship between PFT parameters and OSA in patients with pSS. In our study, no relationship was found between the presence of OSA in pSS and the results of spirometry and DLCO. Not only pSS but also generally under the title of interstitial lung disease (ILD), how respiratory functions affect OSA is a question that remains unanswered. Mermigkis et al. investigated sleep-disordered breathing in patients with Idiopathic Pulmonary Fibrosis (IPF) and a partial relationship was found between low FVC and AHI, and a statistically significant relationship was found between FVC and REM AHI. This 
Table 2 Relationship between the presence of OSA and clinical, demographic, laboratory, pulmonary function tests, and radiologic features in patients with pSS

\begin{tabular}{|c|c|c|c|}
\hline Parameters & pSS-OSAS (-) $(n=7)$ & pSS-OSAS $(+)(n=37)$ & $p$ \\
\hline Sex Female/Male & $6 / 1$ & $36 / 1$ & 0.296 \\
\hline Age (year), mean \pm SD & $44.9 \pm 11.8$ & $58.4 \pm 12.5$ & $0.016 *$ \\
\hline Body Mass Index $\left(\mathrm{kg} / \mathrm{m}^{2}\right)$, mean \pm SD & $24.8 \pm 5.6$ & $29.8 \pm 4.0$ & $0.016^{*}$ \\
\hline Normal (BMI <25), n (\% mean) & $4(28.6)$ & $4(10.8)$ & \\
\hline Overweight (BMI <30), n (\% mean) & $2(28.6)$ & $15(40.5)$ & $0.012 *$ \\
\hline Obese (BMI <40), n (\% mean) & $1(14.3)$ & $18(48.7)$ & \\
\hline Neck circumference $(\mathrm{cm})$, mean \pm SD & $33.1 \pm 2.5$ & $35.3 \pm 2.8$ & 0.092 \\
\hline Duration of illness (year), mean $\pm \mathrm{SD}$ & $5.7 \pm 3.2$ & $5.8 \pm 4.8$ & 0.619 \\
\hline \multicolumn{4}{|l|}{ Smoking } \\
\hline Smoking (pack-year), n (\% mean) & $1.7 \pm 4.9$ & $5.1 \pm 9.7$ & 0.286 \\
\hline Never smoker $\mathrm{n}$ (\% mean) & $6(85.8)$ & $24(64.9)$ & \\
\hline Former smoker n ( $\%$ mean $)$ & $0(0)$ & $9(24.3)$ & 0.343 \\
\hline Current smoker n ( $\%$ mean $)$ & $1(14.3)$ & $4(10.8)$ & \\
\hline \multicolumn{4}{|l|}{ pSS lab, n (\% mean) } \\
\hline RF positivity & $2(28.6)$ & $12(32.4)$ & 0.999 \\
\hline ANA positivity & $2(28.6)$ & $18(48.7)$ & 0.355 \\
\hline Anti-Ro/SSA positivity & $6(85.7)$ & $19(51.4)$ & 0.119 \\
\hline Anti-La/SSB positivity & $1(14.3)$ & $13(35.1)$ & 0.270 \\
\hline Schirmer test positivity, $\mathrm{n}(\%$ mean) & $3(42.9)$ & $22(59.5)$ & 0.443 \\
\hline Salivary gland biopsy supporting pSS, n (\% mean) & $5(71.4)$ & $21(56.8)$ & 0.682 \\
\hline \multicolumn{4}{|l|}{ Symptoms, n (\% mean) } \\
\hline Dry mouth & $5(71.4)$ & $24(64.9)$ & 0.999 \\
\hline Dry eyes & $3(42.9)$ & $30(81.1)$ & 0.054 \\
\hline \multicolumn{4}{|l|}{ Pulmonary function tests } \\
\hline $\mathrm{FVC}(\mathrm{L})$, mean $\pm \mathrm{SD}$ & $3.03 \pm 0.68$ & $2.64 \pm 0.75$ & 0.112 \\
\hline $\mathrm{FVC}(\%)$, mean $\pm \mathrm{SD}$ & $96.0 \pm 10.9$ & $102.6 \pm 17.8$ & 0.360 \\
\hline FEV1 (L), mean \pm SD & $2.33 \pm 0.48$ & $2.11 \pm 0.57$ & 0.211 \\
\hline $\operatorname{FEV} 1(\%)$, mean \pm SD & $87.8 \pm 7.8$ & $97.6 \pm 18.3$ & 0.177 \\
\hline $\mathrm{FEV} 1 / \mathrm{FVC}(\%)$, mean $\pm \mathrm{SD}$ & $78.1 \pm 6.0$ & $80.0 \pm 7.1$ & 0.327 \\
\hline $\mathrm{DLCO}(\mathrm{mL} / \mathrm{min} / \mathrm{mmHg}), \operatorname{mean} \pm \mathrm{SD}$ & $18.8 \pm 6.2$ & $16.4 \pm 6.0$ & 0.320 \\
\hline $\operatorname{DLCO}(\%)$, mean \pm SD & $77.6 \pm 21.3$ & $74.9 \pm 23.7$ & 0.642 \\
\hline \multicolumn{4}{|l|}{ Radiological findings, $\mathrm{n}(\%)$} \\
\hline Interstitial involvement & $2(28.6)$ & $13(35.1)$ & 0.401 \\
\hline UIP & $0(0.0)$ & $6(16.2)$ & 0.586 \\
\hline LIP & $0(0.0)$ & $4(10.8)$ & 0.999 \\
\hline NSIP & $1(14.3)$ & $2(5.4)$ & 0.413 \\
\hline $\mathrm{OP}$ & $1(14.3)$ & $1(2.7)$ & 0.296 \\
\hline Number of segments held & $1.7 \pm 4.9$ & $4.5 \pm 6.5$ & 0.294 \\
\hline Bronchiectasis & $1(14.3)$ & $12(32.4)$ & 0.654 \\
\hline \multicolumn{4}{|l|}{ Comorbidities, n (\%) } \\
\hline Diabetes mellitus & $1(14.3)$ & $6(16.2)$ & 0.999 \\
\hline Hypertension & $1(14.3)$ & $14(37.8)$ & 0.393 \\
\hline Cardiovascular disease & $0(0.0)$ & $3(8.1)$ & 0.999 \\
\hline \multicolumn{4}{|l|}{ Symptoms suggestive of OSA, $\mathrm{n}(\%)$} \\
\hline EDS & $5(71.4)$ & $28(75.7)$ & 0.999 \\
\hline Snore & $3(42.9)$ & $24(64.9)$ & 0.402 \\
\hline Witnessed apnea & $1(14.3)$ & $12(32.4)$ & 0.654 \\
\hline ESS, mean \pm SD & $5.4 \pm 3.3$ & $5.8 \pm 4.2$ & 0.821 \\
\hline
\end{tabular}

*: $p<0.05$

ANA Anti-nuclear antibody; BMI Body mass index; DLCO carbon monoxide diffusion of the lung capacity; FEVI Forced vital capacity 1 . Second; FVC Forced vital capacity; EDS excessive daytime sleepiness; ESS Epworth Sleepiness Scale; LIP Lymphocytic interstitial pneumonia; $N S I P$ Non-specific intestinal pneumonia; $O P$ organized pneumonia; $O S A$ Obstructive sleep apnea syndrome; $p S S$ Primary Sjögren Syndrome; $R F$ Rheumatoid factor; UIP usual interstitial pneumonia 
Table 3 Comparison of pSS and control group in terms of demographics, presence of OSA, and PSG findings

\begin{tabular}{|c|c|c|c|}
\hline Parameters & pSS group $(n=44)$ & Control $(n=88)$ & $p$ \\
\hline Sex female/male & $42 / 2$ & $88 / 0$ & 0.109 \\
\hline Age (year), mean \pm SD & $56.3 \pm 13.3$ & $54.0 \pm 8.6$ & 0.296 \\
\hline Body mass index $\left(\mathrm{kg} / \mathrm{m}^{2}\right)$, mean $\pm \mathrm{SD}$ & $29.0 \pm 4.6$ & $28.5 \pm 4.0$ & 0.543 \\
\hline \multicolumn{4}{|l|}{ BMI classification } \\
\hline Normal $(\leq 18.5 \mathrm{BMI}<25), n(\%$ mean $)$ & $8(18)$ & $18(21)$ & \multirow{3}{*}{0.593} \\
\hline Overweight $(\leq 25 \mathrm{BMI}<30), n(\%$ mean $)$ & $17(39)$ & $40(46)$ & \\
\hline Obese (BMI $\geq 30), n(\%$ mean $)$ & $19(43)$ & $30(34)$ & \\
\hline Neck circumference $(\mathrm{cm})$, mean $\pm \mathrm{SD}$ & $35.0 \pm 2.8$ & $36.1 \pm 3.1$ & 0.053 \\
\hline Smoking (pack-year) mean \pm SD & $4.6 \pm 9.1$ & $7.3 \pm 11.9$ & 0.190 \\
\hline \multicolumn{4}{|l|}{ Smoking classification, $n(\%)$} \\
\hline Never smoker & $30(68)$ & $51(58)$ & \multirow{3}{*}{0.108} \\
\hline Former smoker & $9(21)$ & $13(15)$ & \\
\hline Current smoker & $5(11)$ & $24(27)$ & \\
\hline \multicolumn{4}{|l|}{ Comorbidities, $n(\%)$} \\
\hline Diabetes mellitus & $7(16)$ & $20(23)$ & 0.492 \\
\hline Hypertension & $15(34)$ & $29(33)$ & 0.999 \\
\hline Cardiovascular disease & $3(7)$ & $2(2)$ & 0.333 \\
\hline \multicolumn{4}{|l|}{ Symptoms suggestive of OSA, $n(\%)$} \\
\hline EDS & $33(76)$ & $56(64)$ & 0.264 \\
\hline Snore & $27(61)$ & $82(93)$ & $<0.001 *$ \\
\hline Witnessed apnea & $13(30)$ & $45(51)$ & $0.030^{*}$ \\
\hline $\mathrm{ESS}$, mean $\pm \mathrm{SD}$ & $5.7 \pm 4.0$ & $6.7 \pm 5.0$ & 0.577 \\
\hline OSA frequency, $n(\%)$ & $37(84)$ & $68(77)$ & 0.359 \\
\hline \multicolumn{4}{|l|}{ OSA severity, $n(\%)$} \\
\hline No & $7(16)$ & $20(23)$ & \multirow{4}{*}{0.150} \\
\hline Mild & $12(27)$ & $11(13)$ & \\
\hline Moderate & $19(43)$ & $38(43)$ & \\
\hline Severe & $6(14)$ & $19(22)$ & \\
\hline REM-dependent OSA & $6(14)$ & $6(7)$ & 0.213 \\
\hline Position-dependent & $6(14)$ & $16(18)$ & 0.680 \\
\hline \multicolumn{4}{|l|}{ PSG findings, $n(\%)$} \\
\hline Obstructive apnea & $39(89)$ & $73(83)$ & 0.548 \\
\hline Central apnea & $9(21)$ & $17(19)$ & 0.999 \\
\hline Mixed apnea & $4(9)$ & $9(10)$ & 0.999 \\
\hline Hypopnea & $42(96)$ & $87(99)$ & 0.999 \\
\hline $\mathrm{SaO} 2$ number below $90 \%$ & $28(64)$ & $67(76)$ & 0.193 \\
\hline Sleep efficiency $(\%)$ & $74.1 \pm 12.1$ & $74.5 \pm 11.5$ & 0.841 \\
\hline $\operatorname{REM}(\%)$, mean $\pm \mathrm{SD}$ & $12 \pm 7$ & $15 \pm 7$ & $0.025 *$ \\
\hline Stage $1(\%)$, mean \pm SD & $9 \pm 8$ & $8 \pm 7$ & 0.088 \\
\hline Stage $2(\%)$, mean \pm SD & $58 \pm 12$ & $59 \pm 19$ & 0.549 \\
\hline Stage $3(\%)$, mean \pm SD & $21 \pm 12$ & $19 \pm 8$ & 0.688 \\
\hline $\mathrm{AHI}$, mean $\pm \mathrm{SD}$ & $15.1 \pm 11.4$ & $17.4 \pm 15.6$ & 0.820 \\
\hline Time to fall asleep $(\mathrm{min})$, mean $\pm \mathrm{SD}$ & $33.3 \pm 28.4$ & $41.5 \pm 32.7$ & 0.059 \\
\hline Snoring index, mean \pm SD & $50.8 \pm 106.3$ & $124.4 \pm 173.1$ & $0.001 *$ \\
\hline Max apnea time $(\mathrm{s})$, mean $\pm \mathrm{SD}$ & $21.7 \pm 16.2$ & $30.5 \pm 25.6$ & $0.028 *$ \\
\hline Max hypopnea time (s), mean $\pm \mathrm{SD}$ & $65.8 \pm 30.1$ & $78.5 \pm 33.3$ & $0.035 *$ \\
\hline $\mathrm{ODI}$, mean $\pm \mathrm{SD}$ & $17.5 \pm 13.4$ & $18.2 \pm 14.6$ & 0.931 \\
\hline REM AHI, mean \pm SD & $28.5 \pm 20.4$ & $26.5 \pm 19.9$ & 0.503 \\
\hline NREM AHI, mean \pm SD & $13.4 \pm 11.1$ & $15.5 \pm 16.2$ & 0.948 \\
\hline Supine AHI, mean \pm SD & $20.2 \pm 18.8$ & $26.1 \pm 24.5$ & 0.319 \\
\hline Non-supine AHI, mean \pm SD & $9.5 \pm 10.8$ & $11.2 \pm 13.3$ & 0.544 \\
\hline
\end{tabular}

${ }^{*} p<0.05$

$A H I$ apnea-hypopnea index, $B M I$ body mass index, EDS excessive daytime sleepiness, ESS Epworth Sleepiness Scale, NREM non-rapid eye movement, $O D I$ oxygen desaturation index, $O S A$ obstructive sleep apnea syndrome, $P S G$ polysomnography, $p S S$ primary Sjögren syndrome, $R E M$ rapid eye movement 
was interpreted as that the risk of sleep apnea might increase in patients with IPF with decreased lung function tests, especially in REM [24]. Lancaster et al. reported no correlation between PFT parameters and AHI in IPF. It was argued that the reason for this might be that the tests were performed sitting rather than in the lying position, which would better reflect the lung volumes during sleep [25]. Pihtili et al. found no relationship between AHI and PFT results in ILD [26]. Although our result is specific to pSS, it is similar to Lancaster et al. and Pihtili et al.; no comparison could be made because there are no data on patients with pSS in the literature.

No studies have investigated the relationship between radiologic lung involvement and OSA in pSS. In ILD, decreased lung volumes, increased respiratory workload, hypoxemia, and increased airway resistance can increase airway collapse during sleep, especially during the REM period, and may cause OSA to occur [26]. AHI was found to be higher in ILD with severe radiologic involvement in the study of Pihtili et al. [26]. In our study, no increase was found in the frequency of OSA in 15 (34.1\%) patients with pSS with radiologic pulmonary involvement. There was no relationship between the presence and severity of radiologic involvement and the presence of OSA. These data are the first in the literature; new studies on this subject will be instructive.

Studies show that patients with pSS and controls have similar total sleep times [7, 27, 28]. Gudbjörnsson et al. found that patients with pSS slept significantly less than patients with rheumatoid arthritis and healthy controls [23]. In our study, patients with pSS had similar total sleep times to the controls. This may be because our control group consisted of patients who had undergone PSG for some reason, rather than being completely healthy. New studies are needed on this subject.

In a study, it was reported that in patients with pSS, the time to fall asleep was longer than for controls [7, 23]. In our study, the time to falling asleep in patients with pSS was similar to that of the control group. Gudbjörnsson et al. and de Goodchild et al. reported that sleep efficiency was significantly lower in the pSS group than in the control group $[23,27]$. In our study, patients with pSS were similar to the control group in terms of sleep efficiency.

Gudbjörnsson et al. found that the duration of stage 1 sleep in patients with pSS was long, and the duration of other stages was similar to that of controls [23]. Usmani et al. found no difference between a control group and a pSS group in terms of sleep times [7]. Looking at other ILDs, it is reported that REM and stage 3 sleep percentage decreased in patients with IPF, scleroderma, and sarcoidosis [26]. Prado et al. reported that stage 3 sleep duration increased and REM sleep percentage decreased in patients with scleroderma [29]. In our study, the percentage of
REM sleep time of patients with pSS was lower than in the control group, whereas other sleep times were found to be similar to the control group. It was also found that the maximum apnea duration, maximum hypopnea duration, and snoring index were decreased in the pSS group compared with the control group. The short duration of maximum apnea and hypopnea in patients with pSS may explain the witnessed apnea and snoring symptoms and the significantly lower snoring index compared with controls. Short apnea and hypopneas may not cause snoring. The most striking points of sleep architecture in patients with pSS were shortened REM sleep duration, shortened maximum apnea, and hypopnea duration. In addition, total sleep time, time to fall asleep, and sleep efficiency are also important components of sleep architecture. These parameters may be explanatory in the symptoms of fatigue and EDS in pSS, but more studies are still needed on this subject.

In two studies investigating OSA in pSS, the ODI value was not examined [7, 8]. In our study, no difference was found between the pSS and control groups in terms of ODI.

Our study's most important limitation is that the retrospectively created control group does not reflect the healthy population. However, such a control group could not be established due to the ethical and cost problems of performing PSG tests on healthy individuals, the closure of PSG laboratories caused by the SARS-CoV-2 virus pandemic, and the difficulty of finding patients. However, the rate of moderate and severe OSA is high in pSS patients (68\% of 37 patients with OSA), similar to the control group. On the other hand, our study's strength is that it is the first study to examine the frequency of OSA in patients with pSS including radiologic findings of lung involvement, spirometry, and DLCO parameters.

To conclude, the frequency of OSA in patients with pSS was $84 \%$, with a decrease in REM\%. Although a correlation between symptoms suggestive of OSA and the presence of radiologic lung involvement, spirometry, and DLCO values with OSA could not be demonstrated, we recommend that physicians be alert for the presence of OSA in all patients with $\mathrm{pSS}$ and investigate OSA using PSG.

Acknowledgements We would like to thank Dr. Hazal Cansu Acar from the Public Health department of Istanbul University-Cerrahpasa, Cerrahpasa Medical Faculty.

Author contributions E.K. and S.B. designed the study. E.K. and S.B. wrote the main manuscript text. E.K, S.B., S.U., and B.M. collected the data and reviewed the manuscript. B.M. analyzed the data. All authors read and approved the final manuscript.

Data availability The data used to support the findings of this study are available from the corresponding author upon request. 


\section{Declarations}

Ethics approval Ethics committee approval for the study was obtained from the Ethics Committee of Istanbul University-Cerrahpasa, Cerrahpasa Medical Faculty (IRB No. 604.01.01-45638). All procedures performed in studies involving human participants were in accordance with the ethical standards of the institutional and/or national research committee and were conducted according to the 1964 Helsinki Declaration and its later amendments or comparable ethical standards.

Informed consent Written informed consent was obtained from all individual participants included in the study.

Conflicts of interest The authors declare that they have no conflict of interest.

Disclosure All authors certify that they have no affiliations with or involvement in any organization or entity with any financial interest (such as honoraria; educational grants; participation in speakers' bureaus; membership, employment, consultancies, stock ownership, or other equity interest; and expert testimony or patent-licensing arrangements), or non-financial interest (such as personal or professional relationships, affiliations, knowledge or beliefs) in the subject matter or materials discussed in this manuscript.

\section{References}

1. Ramos-Casals M, Tzioufas AG, Font J (2005) Primary Sjögren's syndrome: new clinical and therapeutic concepts. Ann Rheum Dis 64:347-354

2. Bowman SJ, Ibrahim GH, Holmes G et al (2004) Estimating the prevalence among Caucasian women of primary Sjögren's syndrome in two general practices in Birmingham, UK. Scand $\mathrm{J}$ Rheumatol 33:39-43

3. Karageorgas T, Fragioudaki S, Bezos A et al (2015) Fatigue in primary Sjogren's Syndrome: clinical, laboratory, psychometric and biological associations. Arthritis Care Res 68:123-131

4. Young T, P. E. Peppard ve D. J. Gottlieb, (2002) Epidemiology of obstructive sleep apnea: a population health perspective. Am J Respir Crit Care Med 165:1217-1239

5. Young T, Palta M, Dempsey J et al (1993) The occurrence of sleep-disordered breathing among middle-aged adults. N Engl J Med 328:1230-1235

6. Karageorgas T, Fragioudaki S, Nezos A et al (2016) Fatigue in primary Sjögren's syndrome: clinical, laboratory, psychometric, and biologic associations. Am Coll Rheumatol 68:123-131

7. Usmani ZA, Hlavac M, Rischmueller M et al (2012) Sleep-disordered breathing in patients with primary Sjögren's Syndrome: a group controlled study. Sleep Med 13:1066-1070

8. Jülich M, Budweiser S, Thoden J et al (2019) Sleep apnea in Sjögren's syndrome potentially influences the EULAR Sjögren's syndrome patient reported index. Mod Rheumatol 29:563-565

9. Vitali C, Bombardieri S, Jonsson R et al (2002) Classification criteria for Sjogren's Syndrome: a revised version of the European criteria proposed by the American-European Consensus Group. Ann Rheum Dis 61:554-558

10. National Institutes of Health (1998) Clinical guidelines on the 1dentification, evaluation, and treatment of overweight and obesity in adults-the evidence report. Obes Res 6(Suppl 2):51S-209S

11. Berry RB, Budhiraja R, Gottlieb DJ et al (2012) Rules for scoring respiratory events in sleep: update of the 2007 AASM manual for the scoring of sleep and associated events. J Clin Sleep Med 8:597-619

12. Uzer F, Toptal AB, Okur U et al (2018) Comparison of positional and rapid eye movement-dependent sleep apnea syndromes. Ann Thorac Med 13:42-47

13. Omobomi O, Quan SF (2018) Positional therapy in the management of positional obstructive sleep apnea-a review of the current literature. Sleep Breath 22:297-304

14. Johns MW (1993) Daytime sleepiness, snoring, and obstructive sleep apnea. The Epworth Sleepiness Scale. Chest 103:30-36

15. Graham BL, Steenbruggen I, Miller MR et al (2019) Standardization of Spirometry 2019 Update, An Official American Thoracic Society and European Respiratory Society Technical Statement. Am J Respir Crit Care Med 200:e70-e88

16. Graham BL, Brusasco V, Burgos F et al (2017) 2017 ERS/ATS standards for single-breath carbon monoxide uptake in the lung. Eur Respir J 49:1600016

17. Tufik S, Santos-Silva R, Taddei JA, Bittencourt LR (2010) Obstructive sleep apnea syndrome in the Sao Paulo Epidemiologic Sleep Study. Sleep Med 11:441-446

18. Peppard PE, Young T, Palta M et al (2000) Longitudinal study of moderate weight change and sleep-disordered breathing. JAMA 284:3015

19. Hoffstein V, Mateika S (1992) Differences in abdominal and neck circumferences in patients with and without obstructive sleep apnoea. Eur Respir J 5:377-381

20. Gundogdu S, Borekci S, Atahan E, Musellim B (2021) Increased frequency of obstructive sleep apnea in the patients with systemic sclerosis. Sleep Breath 25:237-242

21. Wetter DW, Young TB, Bidwell TR et al (1994) Smoking as a risk factor for sleep-disordered breathing. Arch Intern Med 154:2219

22. Hackett KL, Gotts ZM, Ellis J et al (2017) An investigation into the prevalence of sleep disturbances in primary Sjögren's Syndrome: a systematic review of the literature. Rheumatology (Oxford) 56:570-580

23. Gudbjörnsson B, Broman JE, Hetta J et al (1993) Sleep disturbances in patients with primary Sjogren's syndrome. Br J Rheumatol 32:1072-1076

24. Mermigkis C, Chapman J, Golish J et al (2007) Sleep-related breathing disorders in patients with 1diopathic pulmonary fibrosis. Lung 185:173-178

25. Lancaster LH, Mason WR, Parnell JA et al (2009) Obstructive sleep apnea is common in idiopathic pulmonary fibrosis. Chest 136:772-778

26. Pihtili A, Bingol Z, Kiyan E et al (2013) Obstructive sleep apnea is common in patients with interstitial lung disease. Sleep Breath 17:1281-1288

27. Goodchild CE, Treharne GJ, Booth DA, Bowman SJ (2010) Daytime patterning of fatigue and its associations with the previous night's discomfort and poor sleep among women with primary Sjogren's Syndrome or rheumatoid arthritis. Musculoskeletal Care 8:107-117

28. Hilditch CJ, McEvoy RD, George KE et al (2008) Upper airway surface tension but not upper airway collapsibility is elevated in primary Sjögren's Syndrome. Sleep 31:367-374

29. Prado GF, Allen RP, Trevisani VMF et al (2002) Sleep disruption in systemic sclerosis (scleroderma) patients: clinical and polysomnographic findings. Sleep Med 3:341-345

Publisher's note Springer Nature remains neutral with regard to jurisdictional claims in published maps and institutional affiliations. 